\title{
Identificação de respondentes a placebo baseados em sinais de EEG
}

\author{
Maria Helena G. B. Reis*, Nancy L. Garcia.
}

\begin{abstract}
Resumo
Uma melhora nos sintomas não devida ao efeito dos produtos químicos ativos no medicamento é caracterizada como efeito placebo, que é altamente prevalente no tratamento de depressão. Este projeto propõe o estudo estatístico de um experimento clínico placebo-controle aleatorizado para depressão, com objetivo de criar um método classificatório de identificação de respondentes a placebo. Modelos de classes latentes são amplamente utilizados na literatura para identificar subgrupos não observados (respondentes ou não-respondentes a placebo, neste estudo). A probabilidade de pertencer a cada subgrupo é modelada utilizando-se covariáveis como sexo e cronicidade da doença, bem como sinais de eletroencefalografia (EEG). Para reduzir a dimensionalidade do modelo, os sinais de EEG foram primeiramente padronizados e classificados em 5 classes. Por fim, foi utilizado o algoritmo EM (Expectation Maximization) para obter os valores da variável latente, podendo então definir qual grupo dado indivíduo melhor se encaixa.
\end{abstract}

Palavras-chave: Modelos lineares generalizados, Variáveis latentes, Algoritmo EM.

\section{Introdução}

A identificação de pacientes sujeitos a depressão profunda que apresentam uma resposta precoce devido ao efeito placebo é muito importante, pois não só pode orientar os médicos na decisão de quais pacientes devem receber um antidepressivo e quais podem melhorar sem o uso de drogas ativas, como também pode potencialmente levar a melhorias e novos desenvolvimentos na medicina de precisão para o tratamento da depressão, e permitir um foco mais aguçado nos efeitos específicos da droga ativa [1]. O uso de sinais de eletroencefalografia (EEG) é amplamente difundido em estudos clínicos, devido à natureza não invasiva e custo-efetividade [1]. Entretanto, sua capacidade em diferenciar pacientes que podem ter uma resposta precoce devido a um efeito placebo não específico é desconhecida [2]. O objetivo deste trabalho é relacionar a probabilidade de um indivíduo ser suscetível a placebo utilizando sinais de EEG, bem como outras covariáveis como sexo e cronicidade da doença.

\section{Resultados e Discussão}

Nosso banco de dados, além da informação dos EEGs de 96 pacientes, contém como variável resposta a mudança em Escala de Hamilton para Depressão (HAM-D) para cada um desses indivíduos. Esse índice foi a primeira escala de heteroavaliação (aplicada por um observador) da gravidade da depressão criada [3]. Uma vez que a medicação envolvida só passa a fazer efeito após a segunda semana de tratamento, uma mudança positiva no HAM-D em um estágio inicial implica em susceptibilidade maior a placebo. $O$ objetivo da modelagem é agrupar as respostas HAM-D em duas distribuições de probabilidade. Assumimos que as respostas dentro de cada subgrupo sejam normalmente distribuídas e estimamos as médias e variâncias utilizando o algoritmo EM, ver Figura 1.

Foi necessário escalonar e centralizar os resultados dos EEGs para cada indivíduo. Em seguida, pela clusterização por k-means, ilustrada na Figura 2, foram criados coeficientes binários para indicar a classificação das curvas de EEG por grupo, com finalidade de reduzir a dimensionalidade do problema. Por fim, o algoritmo EM obteve as estimativas dos parâmetros bem como dos valores das variáveis latentes do modelo de regressão.

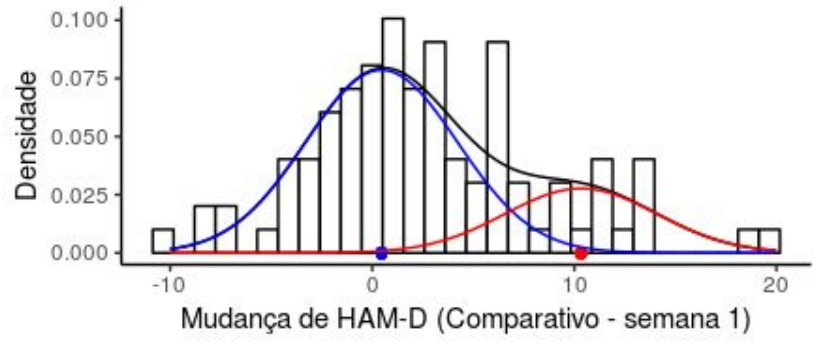

Figura 1. Mudança de HAM-D para 96 pacientes. A curva azul representa a distribuição de não respondentes a placebo e a vermelha os respondentes. A curva em preto é a mistura das curvas azul e vermelha.

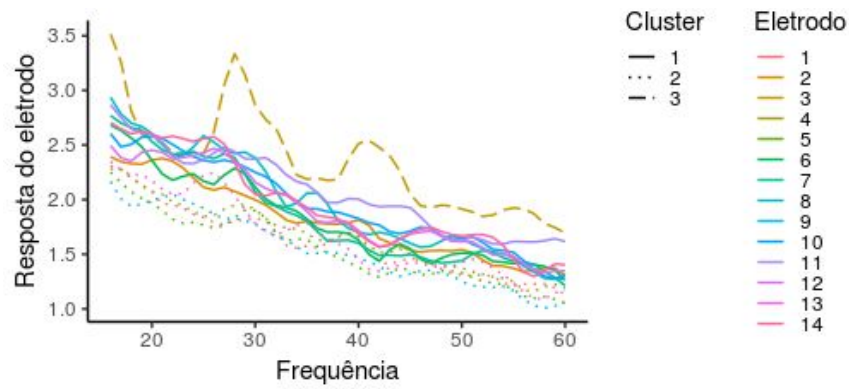

Figura 2. EEGs no domínio da frequência para um indivíduo, agrupadas em três clusters (por forma da linha).

\section{Conclusões}

Foi proposta uma nova forma de redução da dimensionalidade do problema agrupando as curvas de EEG em classes. O modelo obtido, além de descrever satisfatoriamente os nossos dados, produz uma proporção de respondentes a placebo e não respondentes muito similar comparado com o modelo da literatura, $26 \%$ e $74 \%$ para nosso modelo e $17 \%$ e $83 \%$ para o da literatura, respectivamente [1].

\section{Agradecimentos}

Agradecemos ao $\mathrm{PIBIC/CNPq}$ pelo incentivo à pesquisa e a Eva Petkova pela disponibilização do banco de dados.

[1] Jiang, B., Petkova, E., Tarpey, T., \& Ogden, R. T. Latent class modeling using matrix covariates with application to identifying early placebo responders based on EEG signals. Ann. Appl. Stat. 2017; 11(3): 1513-1536.

[2] Wade, E. C., \& Iosifescu, D. V. Using EEG for treatment guidance in major depressive disorder. Biol. Psychiatry Cogn. Neurosci. Neuroimaging 2016; 1(5): 411-422.

[3] Neto, J. G., Júnior, M. S. C., \& von Krakauer Hübner, C. Escala de Depressão de Hamilton (HAM-D). Rev. Fac. Ciênc. Méd. Sorocaba 2001; 3(1): $10-14$. 